\title{
Goal attainment scaling as a measure of meaningful outcomes for children with sensory integration disorders.
}

Zoe Mailloux

Pediatric Therapy Network

Teresa A. May-Benson

Occupational Therapy Associates

Clare A. Summers

The Children's Hospital

Lucy Jane Miller

University of Colorado at Denver and Health Sciences Center

Follow this and additional works at: https://jdc.jefferson.edu/otfp

Z-rbara Brett-Green

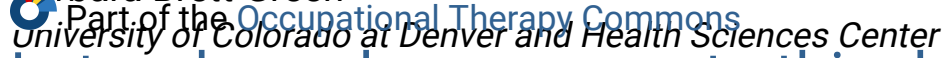

Let us know how access to this document benefits you

See next page for additional authors

Recommended Citation

Mailloux, Zoe; May-Benson, Teresa A.; Summers, Clare A.; Miller, Lucy Jane; Brett-Green, Barbara; Burke, Janice P.; Cohn, Ellen S.; Koomar, Jane A.; Parham, L Diane; Roley, Susanne Smith; Schaaf, Roseann C.; and Schoen, Sarah A., "Goal attainment scaling as a measure of meaningful outcomes for children with sensory integration disorders." (2007). Department of Occupational Therapy Faculty Papers. Paper 46.

https://jdc.jefferson.edu/otfp/46

This Article is brought to you for free and open access by the Jefferson Digital Commons. The Jefferson Digital Commons is a service of Thomas Jefferson University's Center for Teaching and Learning (CTL). The Commons is a showcase for Jefferson books and journals, peer-reviewed scholarly publications, unique historical collections from the University archives, and teaching tools. The Jefferson Digital Commons allows researchers and interested readers anywhere in the world to learn about and keep up to date with Jefferson scholarship. This article has been accepted for inclusion in Department of Occupational Therapy Faculty Papers by an authorized administrator of the Jefferson Digital Commons. For more information, please contact: JeffersonDigitalCommons@jefferson.edu. 


\section{Authors}

Zoe Mailloux, Teresa A. May-Benson, Clare A. Summers, Lucy Jane Miller, Barbara Brett-Green, Janice P. Burke, Ellen S. Cohn, Jane A. Koomar, L Diane Parham, Susanne Smith Roley, Roseann C. Schaaf, and Sarah A. Schoen 


\title{
THE ISSUE IS
}

\section{Goal Attainment Scaling as a Measure of Meaningful Outcomes for Children With Sensory Integration Disorders}

\author{
Zoe Mailloux, Teresa A. May-Benson, Clare A. Summers, \\ Lucy Jane Miller, Barbara Brett-Green, Janice P. Burke, \\ Ellen S. Cohn, Jane A. Koomar, L. Diane Parham, \\ Susanne Smith Roley, Roseann C. Schaaf, Sarah A. Schoen
}

\author{
KEY WORDS \\ - goal attainment scaling (GAS) \\ - pediatric \\ - sensory integration \\ - sensory processing
}

Zoe Mailloux, MA, OTR/L, FAOTA, is Director of Administration, Pediatric Therapy Network, 1815 West 213th Street, Suite 100, Torrance, CA 90501; zoem@PTNmail.org.

Teresa A. May-Benson, ScD, OTR/L, is Research Director, The SPIRAL Foundation; and Clinical Specialty Director, Occupational Therapy Associates, Watertown, MA.

Clare A. Summers, MA, OTR, is Occupational Therapist, The Children's Hospital, Denver, CO.

Lucy Jane Miller, PhD, OTR, FAOTA, is Associate Clinical Professor, Departments of Rehabilitation Medicine and Pediatrics, University of Colorado at Denver and Health Sciences Center; Director, Sensory Therapies and Research (STAR) Center; and Director, KID Foundation, Greenwood Village, CO.

Barbara Brett-Green, PhD, is Assistant Professor, University of Colorado at Denver and Health Sciences Center; Senior Researcher, KID Foundation, Greenwood Village, $\mathrm{CO}$.

Janice P. Burke, PhD, OTR/L, FAOTA, is Professor and Chair, Department of Occupational Therapy; and Dean, wJefferson School of Health Professions, Thomas Jefferson University, Philadelphia.

Ellen S. Cohn, ScD, OTR/L, FAOTA, is Clinical Associate Professor, Boston University-Sargent College of Health and Rehabilitation Sciences, Boston.

Jane A. Koomar, PhD, OTR/L, FAOTA, is Owner and Executive Director, Occupational Therapy Associates, PC, and The SPIRAL Foundation, Watertown, MA.

L. Diane Parham, PhD, OTR/L, FAOTA, is Associate Professor, Division of Occupational Science and Occupational Therapy, University of Southern California, Los Angeles.

Susanne Smith Roley, MS, OTR/L, FAOTA, is Project Director, USC/WPC Comprehensive Program in Sensory Integration, University of Southern California, Los Angeles; and Coordinator of Education and Research, Pediatric Therapy Network, Torrance, CA.

Roseann C. Schaaf, PhD, OTR/L, FAOTA, is Associate Professor, Vice Chair, and Director of Graduate Studies, Department of Occupational Therapy, Thomas Jefferson University, Philadelphia.

Sarah A. Schoen, PhD, OTR, is Clinical Instructor, University of Colorado at Denver and Health Sciences Center; Director of Occupational Therapy, STAR Center; and Senior Researcher, KID Foundation, Greenwood Village, CO.

Goal attainment scaling (GAS) is a methodology that shows promise for application to intervention effectiveness research and program evaluation in occupational therapy (Dreiling \& Bundy, 2003; King et al., 1999; Lannin, 2003; Mitchell \& Cusick, 1998). This article identifies the recent and current applications of GAS to occupational therapy for children with sensory integration dysfunction, as well as the process, usefulness, and problems of application of the GAS methodology to this population. The advantages and disadvantages of using GAS in single-site and multisite research with this population is explored, as well as the potential solutions and future programs that will strengthen the use of GAS as a measure of treatment effectiveness, both in current clinical practice and in much-needed larger, multisite research studies.

Mailloux, Z., May-Benson, T. A., Summers, C. A., Miller, L. J., Brett-Green, B., Burke, J. P., et al. (2007). The Issue IsGoal attainment scaling as a measure of meaningful outcomes for children with sensory integration disorders. American Journal of Occupational Therapy, 61, 254-259.

W th the ultimate aim of enhancing participation and engagement in meaningful life activities, occupational therapists establish goals with individual people and their families that are infinitely unique and diverse (Crepeau, Cohn, \& Schell, 2003). The array of potential outcomes after intervention creates rich clinical practice but makes implementing effectiveness research complex. For more than 40 years (Ayres, 1965, 1966; Parham \& Mailloux, 2004), occupational therapists have identified signs of poor or inefficient sensory processing and motor planning or coordination functions-collectively known as sensory integration disorders - among various clinical populations. Research studies examining the effectiveness of occupational therapy intervention with clients who have sensory integration problems have shown mixed results, as demonstrated by more than 75 original studies, 2 meta-analyses, and 4 review papers (Parham et al., 2007). These studies clearly point out the challenge of defining intervention in a standard way and identifying appropriate outcome measures (Miller, 2003a; Miller \& Kinneally, 1993). Identifying standardized means to capture the diversity of meaningful, functional outcomes that are noted by therapists, families, and individuals who participate in occupational therapy applying a sensory integration approach (OT-SI) presents a special challenge to conducting reliable and relevant effectiveness research. The purpose of this article is to describe the efforts of a collaborative team of occupational therapists to explore the potential of goal attainment scaling (GAS) as a measurement methodology that would capture, in a reliable and valid manner, the diverse gains noted after use of the OT-SI approach.

\section{Goal Attainment Scaling}

GAS is a method originally developed for adults in the mental health arena as a program evaluation tool that facilitates patient participation in the goal-setting process (Kiresuk, Smith, \& Cardillo, 1994). The GAS methodology is congruent with the 
client-centered occupational therapy philosophy because GAS provides a means to identify intervention outcomes that are specifically relevant to individuals and their families. Through the use of interview during goal-setting and posttreatment sessions, the GAS process captures functional and meaningful aspects of a person's progress that are challenging to assess using available standardized measures. Recent studies have found that, although parents value observable sensory and motor changes traditionally reflected in standardized tests, they place greater value on those aspects of functioning that are not readily measured by traditional outcome measures (Cohn, 2001; Cohn, Miller, \& Tickle-Degnen, 2000). Because GAS captures individualized progress that is meaningful to the family, GAS is an appealing methodology for measuring change during and after OT-SI, both in clinical and research applications.

\section{Goal-Writing and Scaling}

When Kiresuk and Sherman (1968) originally developed GAS methodology, they devised a very precise scaling method for writing outcome goals that was based on the probability that a particular outcome would occur. This method, which involved assigning specific numeric values to levels of performance expected to be achieved by the client after intervention, was based on the therapist's experience and knowledge of the client and his or her condition. When applied appropriately, the distance between the levels of the scale is equal and equally distributed around the predicted level of performance. In this model, the emphasis is on conceptualizing goal attainment around the projected outcome level of performance, rather than conceptualizing progress as a linear progression from a baseline or current level of functioning. This concept of GAS as reflecting the probability of occurrence of an outcome is key to allowing one person's goal outcomes to be compared to another person's goal outcomes. Therefore, in writing the goals, the occupational therapist must attempt to (a) accurately predict the level of performance the child is expected to achieve after a specified period of time and (b) identify equal increments above and below the expected level of performance.

In general, a 5 -point scale $(-2$ to +2$)$ is used for scaling goals. Kiresuk et al. (1994) specified that 0 (zero) be used as the predicted expected level of performance, with -1 indicating somewhat less than expected performance (see Table 1). Various other researchers have suggested different designations for the levels within this rating scale. Table 2 summarizes scaling systems suggested in the literature for GAS, as well as the scaling system used in pilot studies of
GAS application in OT-SI (Miller et al., 2007). See Table 3 for a sample GAS goal.

\section{GAS Application}

GAS has been successfully applied in previous occupational therapy effectiveness research in various pediatric settings, including rehabilitation (Lannin, 2003; Mitchell \& Cusick, 1998) and school system (Dreiling \& Bundy, 2003; King et al., 1999). However, previous use of the GAS process was highly individualized to meet the needs of the specific program, resulting in a wide variety of GAS methodologies, some of which had little consistency to the original GAS process (Kiresuk et al., 1994).

\section{GAS Application in Sensory Integration Research}

Single-site research application of GAS. The first known application of GAS in a research protocol for children with sensory integration dysfunction occurred in two pilot studies conducted between 1997 and 2005. The studies examined the effectiveness of OT-SI for children from ages 4 to 12 years who were identified as having atypical responsiveness to sensation (Miller et al., 2007). In these pilot studies, the children participated in OT-SI for 20 sessions over a 10 -week period. Effectiveness of the intervention was measured by examining pretest

Table 1. Scaled Levels of Goal Attainment Scaling

\begin{tabular}{|c|c|}
\hline Rating & Level Description \\
\hline-2 & $\begin{array}{l}\text { Much Less Than Expected Outcome-This level reflects performance that is likely to occur approximately } 7 \% \text { of the time, ranging from } \\
\text { regression to no or minor changes. }\end{array}$ \\
\hline-1 & $\begin{array}{l}\text { Somewhat Less Than Expected Outcome-This level reflects performance that is likely to occur approximately } 21 \% \text { of the time and is } \\
\text { somewhat less than expected for the intervention period. }\end{array}$ \\
\hline 0 & $\begin{array}{l}\text { Projected Performance Expected by the End of the Measurement Period-This level of performance indicates performance to the extent } \\
\text { anticipated at the initiation of treatment for the given measurement period and is expected to occur approximately } 43 \% \text { of the time. }\end{array}$ \\
\hline+1 & $\begin{array}{l}\text { Somewhat More Than Expected Outcome-This level of performance reflects performance that is likely to occur approximately } 21 \% \text { of the } \\
\text { time and indicates somewhat more progress than expected during the intervention period. }\end{array}$ \\
\hline+2 & $\begin{array}{l}\text { Much More Than Expected Outcome-This level reflects performance that is likely to occur approximately } 7 \% \text { of the time and is unusual } \\
\text { because significantly more progress than expected occurred during the measurement period. }\end{array}$ \\
\hline
\end{tabular}

Table 2. Comparison of Goal Scaling Methods Used by Various Researchers

\begin{tabular}{cllll} 
& \multicolumn{3}{c}{ Scaling Method } \\
\cline { 2 - 5 } Level & Ottenbacher \& Cusick (1990) & \multicolumn{1}{c}{ King et al. (1999) } & \multicolumn{1}{c}{ Miller et al. (2007) } & Kiresuk, Smith, \& Cardillo (1994) \\
\hline-2 & Most unfavorable outcome likely & Baseline & Regression from current level & Much less than expected outcome \\
-1 & Less than expected outcome & Less than expected outcome & Current level of performance & Somewhat less than expected outcome \\
0 & Expected level & Expected level & Expected level & Projected level of performance \\
+1 & Greater than expected outcome & Greater than expected outcome & Greater than expected outcome & Somewhat more than expected outcome \\
+2 & Most favorable outcome likely & Much greater than expected outcome & Much greater than expected outcome & Much more than expected outcome \\
\hline
\end{tabular}


CONCERN: Inability to participate in a family dinner due to oversensitivities to textures, tastes, smells, and sound.

GOAL: To be able to participate in a family meal at home, at friends' and relatives' homes, and at a restaurant, by decreasing oversensitivities to textures, smells, taste, and noise.

INTERVENTION PERIOD: 20 sessions

$-2$

Much Less Than Expected Level Less Than Expected Level
0

Expected Level of Performance
$+1$

Better Than Expected Level Much Better Than Expected Level
Tolerates the family eating area during mealtime without signs of discomfort or distress (e.g., crying, gagging, whining, or leaving the table or room), 4 of 5 opportunities.
Tolerates 2 new foods on table Tolerates 2 new foods placed or other family members' plates without signs of discomfort or distress (e.g., crying, gagging, whining, or leaving the table or room), 4 of 5 opportunities. on own plate without signs of discomfort or distress (e.g., crying, gagging, whining, or leaving the table or room), 4 of 5 opportunities.
Takes 1 bite of 2 new foods during a meal without signs of discomfort or distress (e.g., crying, gagging, whining, or leaving the table or room), 4 of 5 opportunities.
Eats multiple bites of 2 new foods without signs of discomfort or distress (e.g., crying, gagging, whining, or leaving the table or room), 4 of 5 opportunities. and posttest changes in behavioral responses using traditional standardized assessments, including the Child Behavior Checklist (Achenbach, 1991), the Short Sensory Profile (McIntosh, Miller, Shyu, \& Dunn, 1999), and the Leiter International Performance Scale-Parent Rating (Roid \& Miller, 1997), as well as physiological measures such as electrodermal responses and heart period variability. Additionally, parents were interviewed at the initiation of the study to establish objectives written according to the GAS process. Objectives were developed to reflect potential intervention outcomes that were meaningful to the parents and family and that were not typically reflected in the standardized and physiological measures. Exit interviews with parents were conducted to evaluate the functional gains made by children.

Results of this study showed some changes on various behavioral and physiological measures. However, GAS measures reflected the most significant gains with a pretreatment and posttreatment difference score $(M=25.31, S D=11.71, p<.0001)$ and a large effect size of 2.16. In contrast, the average effect size of the other outcome measures was .50. Thus, scaling goals using GAS appeared to be the most sensitive means to reflect change in individual children after their participation in occupational therapy. Further, this study demonstrated that GAS could capture individual changes in daily life occupations that are functional, meaningful alterations in occupational performance over a short intervention period in a small sample (Miller et al., 2007).
Multisite clinical application of GAS. In 2001, a federal multisite R21 planning grant from the National Center for Medical Rehabilitation Research (NCMRR) (National Institutes of Health/National Institute of Child Health and Human Development/NCMRR) supported collaboration among four university-based research programs paired with three wellestablished clinical intervention sites. The teams included the University of Colorado Health Sciences Center and The Children's Hospital, Denver; the University of Southern California and Pediatric Therapy Network, Torrance; Boston University and Occupational Therapy Associates-Watertown; and Thomas Jefferson University, Philadelphia. The goal of this grant was to form a multisite team of clinicians and researchers to plan for collaborative effectiveness studies of OT-SI. The collaborative team identified three primary issues that had to be addressed before the initiation of multisite intervention projects: (a) identify comprehensive physiological and behavioral evaluation measures for children thought to have sensory integration disorders, (b) identify the primary characteristics of OT-SI so intervention would be reliable across sites and develop a means of assuring fidelity to this intervention, and (c) identify measurement methodologies that would reflect the functional and meaningful gains made after OT-SI (Miller, 2003b).

The collaborative team identified GAS as a potential outcome measure methodology that could capture and quantify individual functional changes. The therapists at the three clinical sites examined the use of GAS to measure change in clinical practice on a trial basis as a part of their facilities' ongoing program evaluation. All of the clinical sites routinely developed therapeutic goals for every child receiving services at their facility as part of their regular intervention programs, so GAS was easily incorporated into this process.

To implement the GAS process in the clinical settings, primary GAS goal writers were identified and trained. The occupational therapists practiced writing several goals and received feedback from members of the collaborative team. A general procedure for goal writing and scaling was developed and agreed on by all therapists to ensure similar increments for scaling. Next, each site used the GAS procedure with several children in their facility. All therapists met with parents in an initial goal-setting meeting and wrote $3-5$ scaled goals per participating child. All children received 20-30 sessions of OT-SI, usually provided for $1 \mathrm{hr}$, twice per week. After all sessions were completed, a follow-up meeting was conducted with the parents to rate the children's progress on the goals. Three months after implementing the GAS process in the clinical setting, participants from the three clinical sites compared the application of GAS in their individual programs, identified strengths and weaknesses of GAS, and made recommendations for application to multisite research.

The team concluded that

- GAS was a sensitive measure of clinical change over a short period of intervention because all children across the sites 
demonstrated the expected level of change or better at follow-up.

- Each site noted that the parents involved in the GAS process greatly valued the individualized goals and appreciated that functional and meaningful aspects of outcomes were addressed.

- The GAS goal-writing therapists from the clinical sites differed in their interpretation of the meaning of some GAS concepts reported in the literature (such as "expected level of performance") and in their use of the scaling system. The multiple therapists involved in the multisite clinical project and the geographic distances between them resulted in less consistency in goal wording and relative distance between ratings (e.g., 0 to $1 ; 1$ to 2 ), or scaling, when writing GAS objectives, than that previously achieved in a single site. Thus, the informal, peer-training model that had been successful in the single-site pilot research study was not as effective for long-distance multisite training. Consistency between sites was viewed as crucial for future implementation of multisite research.

- Each site concurred that the GAS process held potential application to both clinical practice as well as research; however, the time demands of the interview and follow-up process that was inherent in the application of GAS made routine clinical use challenging.

In conclusion, consistent with the initial pilot study, the collaborative team found that GAS was effective in identifying out- comes that were meaningful to the parents and family. However, although GAS application was consistent within single sites, increased uniformity of the GAS process across multiple sites was needed before initiation of a collaborative multisite project.

\section{Reliability of GAS Application}

Reliable writing of goals was identified as a primary need for replicable effectiveness studies with children who have sensory integration disorders. The collaborative team noted that reliability needed to be established across and within sites for each of the following steps:

- Identifying the individual goals that are expected to change as a result of the intervention

- Scaling the goals into the levels of expected outcomes

- Determining which level best reflects the person's change during intervention and rating the scaled goals

\section{Goal Setting and Goal Follow-Up Processes}

In most clinical settings where OT-SI is provided, the child's occupational therapist usually initiates writing goals that will be used to evaluate progress. Best practice in occupational therapy includes the parents in the goal-setting process and, ideally, the child. Intervention goals should be functional and reflect occupational performance areas valued by the child and family. Methods of gathering information from parents to develop goals have varied from asking direct questions about difficulties to using open-ended interview methods allowing parents to generate areas of need with minimal guidance or bias from the therapist (Miller \& Summers, 2001).

When developing a GAS process for use with children who have sensory integration dysfunction, the collaborative team recommended the following steps:

- The occupational therapist trained to write the GAS goals should review the child's records, including evaluation and sensory history, before conducting the parent meeting. To increase objectivity in reviewing progress, the GAS goal-writing therapist and the therapist providing the intervention should not be the same person. This distinction would be important in an efficacy study in which control groups of children who did and did not receive OT-SI were included.

- The parent goal-setting meeting should take place using a semistructured interview with consistent structure across sites. See Figure 1 for examples of guiding questions.

- The GAS goal-writing therapist should write five scaled goals according to the criteria described below and in accordance with the GAS training program.

- The GAS goal-writing therapist should review the scaled goals with the parents to validate the expected level of
a. Tell me about your child. What are his/her strengths, his/her weaknesses?
b. What has led you to seek services for your child?
c. What concerns you most about your child? Tell me more specifically about. ...
d. What is a typical (day, week) like for him/her?
e. Tell me about your family's life. What kinds of things do you like to do? What is easy or hard for your family or its members?
f. Tell me about what you or other family members need to do to have things go smoothly for your child.
g. (Review the child's evaluation and ask questions regarding functional areas of difficulty.) For example: I notice that (e.g., mealtime) seems to be hard for him/her. Can you tell me more about that?
h. (After functional areas are covered): Tell me more specifically about from the evaluation). (each specific sensory area identified as problematic
i. (Ask if appropriate): Our evaluations showed some difficulties/delays with Is this something that has been of concern to you?
j. What are some goals you have for your child in the next 3 months or so? (Time frame may be variable.)
k. Looking ahead, what are some of the things you are hoping for your child?
I. Imagine we are sitting here talking 3 months [variable] from now. What changes would you like to see by that time?

Figure 1. Guiding questions for parents during goal-setting interview. 
performance. (The full scaled objectives are not shared at this time to minimize response shift bias, e.g., tendency to overrate progress.) The parents rank-order the goals based on importance to them, with a score of 1 being the most important and 5 being the least.

- For each child, goals should address specific need areas that reflect the International Classification of Function (World Health Organization, 2002) taxonomy or the Occupational Therapy Practice Framework: Domain and Process (American Occupational Therapy Association, 2002). These areas are identified as priorities for families of children receiving occupational therapy services (Cohn et al., 2000; Cohn, Dunphy, Pascal, \& Miller, 2001). Goal areas include body function or structure, client factors, activity function, participation, familyrelated concerns, and context or environmental accommodations.

- After a standard designated intervention period, a follow-up meeting should be conducted with the parents to determine the child's progress on the scaled goals. The occupational therapist who wrote the goals (but not the treating therapist) should conduct a semistructured exit interview.

- After the exit-interviewer determines the child's current level of functioning based on the exit interview, an unscored copy of the scaled goals should be given to the parents, who rate their perception of their child's progress on the goals. This provides feedback regarding the accuracy of the therapist ratings.

\section{Application of GAS to Multisite Programs}

This preliminary collaborative application of the GAS process, as well as an extensive review of the literature, determined that GAS has been an effective outcome measure within single-site studies and holds promise for use in multisite applications. Further empirical research on validity and reliability across sites is necessary before GAS can be a reliable methodology for a multisite study. Specific reliability concerns are (a) consistent goal selection, wording, and measurability of the scaled goals; (b) consistency in establishing increments between levels of the scaled goals; and (c) interrater reliability among occupational therapists both within and across sites. In addition to the reliability concerns, collaboration and discussion of the challenges of applying GAS in a multisite setting resulted in the development of a revised standard GAS goal-setting procedure as well as a GAS administration and scoring manual for use across the clinical settings. The collaborative team recommended that the next steps include development of a training program to be used at all of the clinical sites, testing of interrater reliability within and across sites for initial and postintervention GAS rating, and determination of validity of parent report by comparing post-intervention parent interviews with observations of the child.

\section{Conclusion}

GAS has unique application as an applied research tool, especially if outcomes are variable and standardized tests are not available. GAS is especially promising for occupational therapy because it captures the individuality of the meaningful and relevant changes in occupational performance that have previously been difficult to measure. The research planning collaborative project discussed here represents a new application of GAS across multiple sites. Reliable use of GAS has the potential to address important concerns related to treatment effectiveness.

Previous studies using GAS have varied methodologically and have rarely addressed reliability or validity issues inherent in the application of the GAS process. GAS requires that the goal-writing occupational therapists accurately (a) identify goal areas important to families and clients, (b) identify the client's projected outcome, (c) scale the objectives, and (d) rate performance at follow-up after intervention. Thus, it is critical for the GAS goal writers to have interrater reliability and for the goals to measure valid outcomes that reflect changes valued by the child and his or her family. For research measuring the effectiveness of occupational therapy intervention, these reliability and validity issues assume even greater importance. Considering the potential value of this method in occupational therapy, especially in application to children with sensory integration disorders in which outcomes of intervention are typically diverse and highly individualized, GAS offers therapists a unique method of capturing outcomes that are truly meaningful to children and their families.

\section{References}

Achenbach, T. M. (1991). Manual for the Child Behavior Checklist/4-18 and 1991 Profile. Burlington: University of Vermont, Department of Psychiatry.

American Occupational Therapy Association. (2002). Occupational therapy practice framework: Domain and process. American Journal of Occupational Therapy, 56, 609-639.

Ayres, A. J. (1965). Patterns of perceptual-motor dysfunction in children: A factor analytic study. Perceptual and Motor Skills, 20, 335-368.

Ayres, A. J. (1966). Interrelationships among perceptual-motor functions in children. American Journal of Occupational Therapy, 20, 68-71.

Cohn, E. (2001). Parent perspectives of occupational therapy using a sensory integration approach. American Journal of Occupational Therapy, 55, 285-294.

Cohn, E. S., Dunphy, K., Pascal, N., \& Miller, L. J. (2001, December). Using the ICIDH-2 framework to document outcomes of occupational therapy. Sensory Integration Special Interest Section Quarterly, 24, 1-3, 6 .

Cohn, E., Miller, L. J., \& Tickle-Degnen, L. (2000). Parental hopes for therapy outcomes: Children with sensory modulation disorders. American Journal of Occupational Therapy, 54, 36-43.

Crepeau, E. B., Cohn, E. S., \& Schell, B. A. B. (Eds.). (2003). Willard and Spackman's occupational therapy (10th ed.). Philadelphia: Lippincott, Williams \& Wilkins.

Dreiling, D. S., \& Bundy, A. C. (2003). Brief Report-A comparison of consultative model and direct-indirect intervention with preschoolers. American Journal of Occupational Therapy, 57, 566-569.

King, G. A., McDougall, J., Tucker, M. A., Gritzan, J., Malloy-Miller, T., Alambets, P., et al. (1999). An evaluation of functional, school-based therapy services for children with special needs. Physical and Occupational Therapy in Pediatrics, 19, 5-29.

Kiresuk, T. J., \& Sherman, R. E. (1968). Goal attainment scaling: A general method for 
evaluating community mental health programs. Community Mental Health Journal, 4, 443-453.

Kiresuk, T. J., Smith, A., \& Cardillo, J. E. (1994). Goal attainment scaling: Applications, theory and measurement. Hillsdale, NJ: Erlbaum.

Lannin, N. (2003). Goal attainment scaling allows program evaluation of a home-based occupational therapy program. Occupational Therapy in Health Care, 17, 43-54.

McIntosh, D. N., Miller, L. J., Shyu, V., \& Dunn, W. (1999). Overview of the Short Sensory Profile. In W. Dunn (Ed.), The sensory profile: Examiner's manual (pp. 59-73). San Antonio, TX: Psychological Corporation.

Miller, L. J. (2003a). Empirical evidence related to therapies for sensory processing impairments. Communiqué, 31(5), 34-37.

Miller, L. J. (2003b). Outcome of sensory based intervention after birth trauma: Final report for NIH Planning Grant RFA \#1R21HD/ AR41614-01. Retrieved December 11, 2006, from www.spdnetwork.org/research.

Miller, L. J., \& Kinneally, M. (1993). Researching the effectiveness of sensory integration. Sensory Integration Quarterly, 21(2), 2-7.

Miller, L. J., Schoen, S. A., James, K., \& Schaaf, R. C. (2007). Lessons learned: A pilot study of occupational therapy effectiveness for children with sensory modulation disorder. American Journal of Occupational Therapy, 61, 161-169.

Miller, L. J., \& Summers, C. (2001). Clinical applications in sensory modulation dysfunction: Assessment and intervention considerations. In S. S. Roley, E. I. Blanche, \& R. C. Schaaf (Eds.), Understanding the nature of sensory integration with diverse populations (pp. 247-274). San Antonio, TX: Therapy Skill Builders.

Mitchell, T., \& Cusick, A. (1998). Evaluation of a client-centered pediatric rehabilitation programme using goal attainment scaling. Australian Occupational Therapy Journal, 45, 7-17.

Ottenbacher, K. J., \& Cusick, A. (1990). Goal attainment scaling as a method of clinical service evaluation. American Journal of Occupational Therapy, 44, 519-525.

Parham, L. D., Cohn, E. S., Spitzer, S., Koomar J. A., Miller, L. J., Burke, J. P., et al. (2007). Fidelity in sensory integration intervention research. American Journal of Occupational Therapy, 61, 216-227.

Parham,L.D.,\& Mailloux,Z. (2004). Sensory integration. In J. Case-Smith, A. Allen, \& P. N. Clark (Eds.), Occupational therapy for children (pp. 307-352). St. Louis, MO: Mosby.

Roid, G. H., \& Miller, L. J. (1997). Leiter International Performance Scale-Revised. Wood Dale, IL: Stoelting.

World Health Organization. (2002). International classification of functioning, disability and health. Geneva, Switzerland: Author.

\section{Attention Administrators, Managers, Business Owners, Educators!}

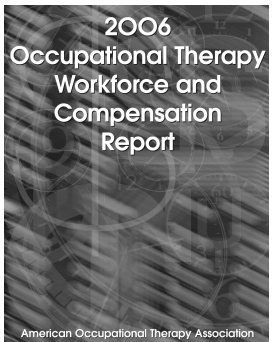
135 pages, 2006

\section{Occupational Therapy Workforce and Compensation Report}

By American Occupational Therapy Association

ISBN-13: 978-1-56900-231-5 ISBN-10: $1-56900-231-2$

A full range of data and analysis in this report gives the detailed picture of today's occupational therapy workforce and key insights into important issues and trends. Based on more than 3,000 responses to AOTA's statistically rigorous Workforce Survey, the report

- Presents overall compensation data and specific benefits for full- and part-time occupational therapists and occupational therapy assistants;

- Details work setting profiles, including academia, hospital (non-mental health), mental health, long-termcare/skilled-nursing facility, schools/early intervention, home health, freestanding outpatient, and community;
- Describes work setting snapshots, practitioner profiles, education and experience, main areas of responsibility, hours worked, overall compensation and specific benefits, and more;

- Looks at fieldwork supervision and direct client treatment metrics, including documentation responsibilities;

- Describes typical reasons for changing jobs, patterns of contract and self-employment, and other workforce issues;

- Presents nearly 100 charts and graphs.

Order your complete report today! Order \#1100-J • \$49 AOTA Members • \$69 Nonmembers
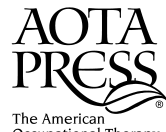
The American Occupational The
Association, Inc. 